\title{
Carrier selective, passivated contacts for high efficiency silicon solar cells based on transparent conducting oxides
}

\author{
David L. Young, William Nemeth, Sachit Grover, Andrew Norman, Hao-Chih Yuan, \\ Benjamin G. Lee, Vincenzo LaSalvia, Paul Stradins \\ National Renewable Energy Laboratory, Golden, CO USA
}

\begin{abstract}
We describe the design, fabrication and results of passivated contacts to n-type silicon utilizing thin $\mathrm{SiO}_{2}$ and transparent conducting oxide layers. High temperature silicon dioxide is grown on both surfaces of an n-type wafer to a thickness $<50 \AA$, followed by deposition of tin-doped indium oxide (ITO) and a patterned metal contacting layer. As deposited, the thin-film stack has a very high $\mathrm{J}_{0 \text {,contact, }}$ and a non-ohmic, high contact resistance. However, after a forming gas anneal, the passivation quality and the contact resistivity improve significantly. The contacts are characterized by measuring the recombination parameter of the contact $\left(\mathrm{J}_{0 \text {,contact }}\right)$ and the specific contact resistivity $\left(\rho_{\text {contact }}\right)$ using a TLM pattern. The best ITO/SiO ${ }_{2}$ passivated contact in this study has $J_{0, \text { contact }}=92.5 \mathrm{fA} / \mathrm{cm}^{2}$ and $\rho_{\text {contact }}=11.5 \mathrm{mOhm}-\mathrm{cm}^{2}$. These values are placed in context with other passivating contacts using an analysis that determines the ultimate efficiency and the optimal area fraction for contacts for a given set of $\left(\mathrm{J}_{0, \text { contact }}, \rho_{\text {contact }}\right)$ values. The ITO $/ \mathrm{SiO}_{2}$ contacts are found to have a higher $\mathrm{J}_{0 \text {,contact }}$, but a similar $\rho_{\text {contact }}$ compared to the best reported passivated contacts.
\end{abstract}

(C) 2014 Published by Elsevier Ltd. This is an open access article under the CC BY-NC-ND license

(http://creativecommons.org/licenses/by-nc-nd/3.0/).

Peer-review under responsibility of the scientific committee of the SiliconPV 2014 conference

Keywords: Silicon solar cells, passivated contacts, $\mathrm{SiO}_{2}$, ITO

\section{Introduction}

As bulk silicon PV wafer lifetimes progressively improve, the need for low recombination, passivated contacts to high efficiency solar cells increases. Contacts can be characterized by their ability to passivate the surface of the $\mathrm{Si}$ wafer through their recombination parameter $\left(J_{0, \text { contact }}\right)$ and by their contact resistivity $\left(\rho_{\text {contact }}\right)$. As other recombination pathways are reduced these two contact parameters can greatly influence the efficiency of the device and set the optimum contact area fraction coverage. One of the best examples of a passivated contact solar cell is the $\mathrm{Si} / \mathrm{a}-\mathrm{Si} / \mathrm{ITO}$ heterojunction device which reached an impressive $\mathrm{V}_{\text {oc }}$ of $750 \mathrm{mV}$ due to extremely low 
recombination at the passivated contacts.[1] Recently $\mathrm{Si} / \mathrm{SiO}_{2} /$ polycrystalline silicon (pc-Si) passivating contacts have also given excellent results.[2-4] Si/a-Si/ITO contacts have very low $J_{0, \text { contact }} \sim 5 \mathrm{fA} / \mathrm{cm}^{2}$, but relatively high contact resistivity $\rho_{\text {contact }} \sim 0.3 \mathrm{ohm}-\mathrm{cm}^{2}$ which may limit them to unity contact area fractions to avoid high series resistance. The $\mathrm{Si} / \mathrm{SiO}_{2} / \mathrm{pc}-\mathrm{Si}$ contacts have very good $J_{0, \text { contact }} \sim 9 \mathrm{fA} / \mathrm{cm}^{2}$ and low $\rho_{\text {contact }} \sim 10 \mathrm{mOhm}-\mathrm{cm}^{2}$ allowing contact area fractions less than one. Some of the drawbacks of the Si/a-Si/ITO contacts are the parasitic optical absorption loss in the doped a-Si layers, a narrow processing window including temperatures $<250{ }^{\circ} \mathrm{C}$, and the need for ultra-clean wafer surfaces before the deposition of the a-Si layer. This contact has proven to be difficult to reproduce between laboratories. The $\mathrm{Si} / \mathrm{SiO}_{2} / \mathrm{pc}-\mathrm{Si}$ contact of Feldmann et al.[4] also has excellent passivation, but requires a high temperature anneal $\left(\sim 850{ }^{\circ} \mathrm{C}\right)$ for optimum performance. This paper explores the use of a thin silicon oxide layer and a transparent conducting oxide (TCO) contact layer to form a passivated contact to n-type silicon. The thin silicon oxide layer provides good chemical passivation, yet allows electrons in the silicon to tunnel to available energy states in the TCO. Figure 1a shows the band alignments, bandgaps and Fermi level positions for the $\mathrm{Si} / \mathrm{SiO}_{2} /$ ITO contact discussed here. The diagram was constructed using measured carrier densities (from Hall effect) and a density-of-states effective mass value for degenerate ITO along with measured work function values.[5-7] Though the conduction band minimum levels do not align between the Si and ITO, the Fermi levels do align when the ITO is heavily degenerate. Figure $1 \mathrm{~b}$ illustrates that transport of electrons between the Si and the ITO is favourable, but transport of holes is not, due to a large valence band offset. These band alignments should make the contacts selective to electrons due to the lack of available receiving states for minority carriers tunnelling across the thin silicon oxide. The advantages of these band-offset, carrier-selective contacts are three fold:

1) Band offsets provide majority carrier selectivity, without the use of heavy majority carrier doping in the silicon to reflect minority carriers. Lower doping in the silicon lowers Auger recombination at the contact.

2) Less optical absorption in the TCO layer due to a higher bandgap than polysilicon and a-Si if used on the sunny-side surface of the cell. An index of refraction of $n \sim 2$ for most TCOs may also be beneficial for antireflective coatings and photon management within the Si cell.

3) Lower processing temperatures, compared with polysilicon, [4] but higher processing temperatures than aSi contacts.[1] The former may help to preserve bulk wafer lifetime, while the latter may allow for more traditional ink-based contact processing and other passivated surfaces needing moderately high annealing steps (e.g. SiNx).

These advantages make TCO based, passivating contacts worth exploring for high efficiency solar cells. We will describe in this paper $\mathrm{Si} / \mathrm{SiO}_{2} / \mathrm{ITO}$ passivating contacts to both $\mathrm{n}$ and $\mathrm{n}+$ wafer surfaces. We will then compare these contacts to the best reported $\mathrm{Si} / \mathrm{a}-\mathrm{Si}$ and $\mathrm{Si} / \mathrm{SiO}_{2} / \mathrm{pc}-\mathrm{Si}$ contacts by using an analytical model to optimize device
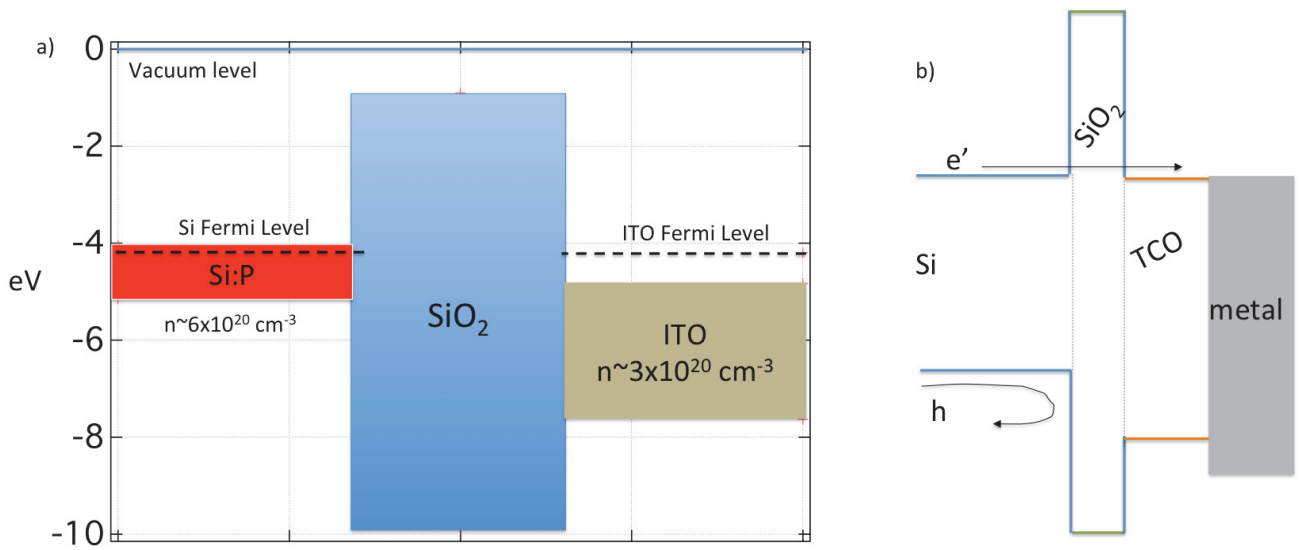

Fig. 1. a) Band alignment diagram for $\mathrm{Si} / \mathrm{SiO}_{2} / \mathrm{ITO}$ contact. b) Simplified band alignment diagram illustrating electron and hole transport at the $\mathrm{Si} / \mathrm{SiO}_{2} / \mathrm{ITO}$ interface. 
efficiency and contact area fraction as a function of $\mathrm{J}_{0 \text {,contact }}, \rho_{\text {contact. }}$

\section{Experiment}

To test $\mathrm{Si} / \mathrm{SiO}_{2} / \mathrm{ITO}$ passivated contacts we grew thick $\mathrm{SiO}_{2}$ layers on both $\mathrm{n}+$ (P-diffused) and undiffused surfaces of n-type 1-10 ohm-cm CZ wafers. The $\mathrm{SiO}_{2}$ layers were then thinned to below $50 \AA$ using a $2 \% \mathrm{HF}$ etchant solution. The thickness of the $\mathrm{SiO}_{2}$ layers were monitored by ellipsometry between etch times. After each thickness measurement the wafers were also measured with a Sinton lifetime tester to extract the implied open circuit voltage $\left(\mathrm{iV}_{\text {oc }}\right)$ values. Fig. 2 shows how $\mathrm{iV}_{\text {oc }}$ varies as a function of $\mathrm{SiO}_{2}$ thickness. Note that $\mathrm{iV}_{\text {oc }}$ does not start to be affected until the thickness of the $\mathrm{SiO}_{2}$ is below about $30 \AA$. This is approximately the same thickness where tunneling begins to be allowed across $\mathrm{SiO}_{2}$. [8]

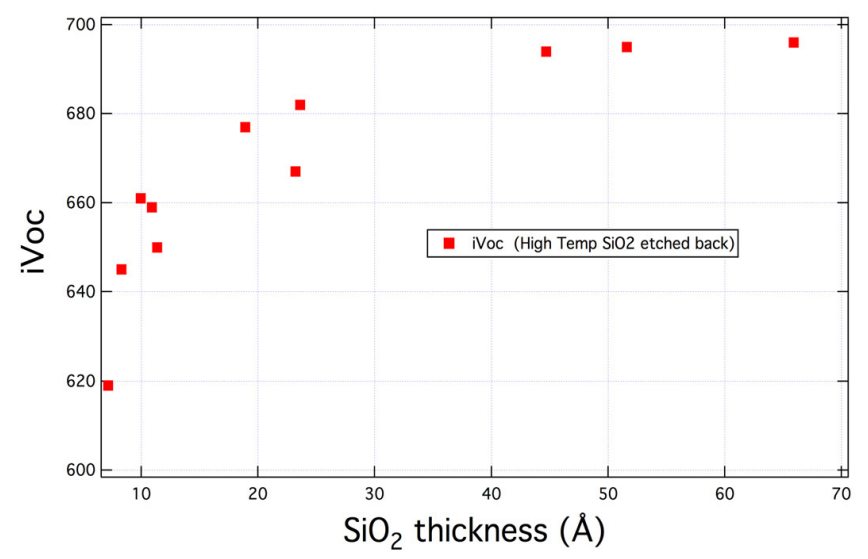

Fig. 2. $\mathrm{iV}_{\text {oc }}$ as a function of etched $\mathrm{SiO}_{2}$ thickness.

Using the thinned oxide we next sputter deposited ITO layers $(70-80 \mathrm{~nm})$ on both sides of the wafer at a deposition temperature of approximately $200{ }^{\circ} \mathrm{C}$. The sputtering conditions were $5 \mathrm{mT}$ of $\mathrm{Ar}$ and $\mathrm{O}_{2}$ using a 13.56 $\mathrm{MHz}$ RF source on a $10 \%$ Sn doped indium oxide target. A series of forming gas anneals were used to help improve the passivation quality. Sinton lifetime testing was done after each process step.

\section{1. $n+$ surface passivation}

n-type, 1-10 ohm-cm Cz, single-side polished wafers were ion implanted with $\mathrm{P}\left(10 \mathrm{keV}, 3 \mathrm{e} 14 \mathrm{~cm}^{-2}\right.$ on the polished side) and then annealed to heal implant damage and form a $102 \AA$ thick $\mathrm{SiO}_{2}$ passivation layers on both sides. Following the implant anneal, the sheet resistance of the $\mathrm{n}+$ layer was $116 \mathrm{Ohm} / \mathrm{square}$. The emitter saturation current density, $J_{0}$, and $i V_{o c}$ were measured on the wafers using a Sinton lifetime tester in the transient or generalized mode. Line 1 of Table 1 shows these values for a wafer following the post-implant anneal. Next, the rough surface of the wafer was protected with photoresist while the polished surface was exposed to a $2 \% \mathrm{HF}$ etch to thin only the oxide on the smooth side to $\sim 17 \AA$. The protected rough surface maintained its as-deposited passivation level. The passivation quality of the contact decreases only slightly for this thin layer (lower $i V_{o c}$ on line 2, Table 1). Next, the photoresist was removed from the rough side of the wafer and a $70 \mathrm{~nm}$ thick ITO layer was deposited by RF magnetron sputtering onto both sides of the wafer. This time, the passivation quality of the wafer was severely diminished (line 3, Table 1) most likely due to $\mathrm{H}$ effusion in the heated, vacuum sputtering environment or due to sputter damage of the $\mathrm{SiO}_{2}$ layer. A metal (Ti/Pd/Ag/Pd) TLM pattern, deposited onto the ITO and isolated by etching down to the $\mathrm{SiO}_{2}$ between the contacts, gave a contact resistivity value of 540 milliOhm-cm ${ }^{2}$ and a non-ohmic IV curve. Next, the sample was annealed for 30 minutes at $400{ }^{\circ} \mathrm{C}$ in forming gas. Following this anneal the passivation quality of the contact increased significantly (lower $J_{0}$, higher $i V_{o c}$ ) and the 
Table 1. Passivation parameters for an $\mathrm{Si} / \mathrm{SiO}_{2} / \mathrm{ITO}$ contact on an $\mathrm{n}+$ surface.

\begin{tabular}{llll}
\hline Sample state & $J_{\text {oTotal }}\left(\mathrm{fA} / \mathrm{cm}^{2}\right)$ & $i V_{\text {oc }}(\mathrm{mV})$ & $\begin{array}{l}\text { Contact resistivity } \\
\left(\mathrm{mOhm}-\mathrm{cm}^{2}\right)\end{array}$ \\
\hline $\begin{array}{l}\text { 1- Post implant anneal } \\
\left.+\mathrm{SiO}_{2} \text { (102 } \mathrm{A}\right)\end{array}$ & 230 & 636 & $\mathrm{~N} / \mathrm{A}$ \\
2- Thinned $\mathrm{SiO}_{2}(17 \AA)$ & 200 & 634 & $\mathrm{~N} / \mathrm{A}$ \\
3- ITO (70 nm) & 1700 & 555 & $\begin{array}{l}\text { Si/SiO2/ITO/Metal } \\
537 \text { (non-ohmic) }\end{array}$ \\
4- FGA (30 mins, 400C) & 553 & & 2.5 (ohmic) \\
& & 614 & 1.8 (ohmic) \\
\hline
\end{tabular}

contact became ohmic with a low contact resistivity of 2.5 milliOhms- $\mathrm{cm}^{2}$ (line 4, Table 1). A second forming gas anneal at $400{ }^{\circ} \mathrm{C}$ for 50 mins continued to improve the passivation quality of the contact (line 5, Table 1) almost back to the original level of passivation (line 2, Table 1), and reduced the contact resistivity even lower. The contact is about five-times lower in $J_{0, \text { total }}$ than a direct metal-to-Si contact, and has an excellent $\rho_{\text {contact }}$ that is comparable to a metal/Si contact.[9] Temperature dependent IV data revealed that the contact is ohmic down to $125 \mathrm{~K}$ with an activation energy of the resistance equal to $17 \mathrm{meV}$. It is interesting to note that both the passivation quality and the transport across the $\mathrm{SiO}_{2}$ improved significantly following the forming gas anneals. Experiments are on-going to understand the passivation and the electron transport mechanisms affected by the anneals and to reveal if the $\mathrm{ITO} / \mathrm{SiO}_{2} / \mathrm{Si}$ contact is truly hole blocking, as predicted.

\section{2. $n$ - surface passivation}

In a second experiment a high lifetime $(1-10 \mathrm{ohm}-\mathrm{cm})$ single-side polished $\mathrm{FZ}$ wafer was used to grow a $\mathrm{Si} / \mathrm{SiO}_{2} / \mathrm{ITO}$ contact to an undoped n-type surface. A thick $\mathrm{SiO}_{2}$ layer $(900 \AA)$ was grown on both sides of the wafer at high temperatures to achieve excellent passivation (Table 2, line 1). The $\mathrm{SiO}_{2}$ layers were both systematically thinned with the $2 \% \mathrm{HF}$ solution followed by Sinton lifetime tester measurements to record the passivation quality (Table 2, lines 2-4). Once the $\mathrm{SiO}_{2}$ layer achieved a thickness of less than $50 \AA$ an $80 \mathrm{~nm}$ ITO layer was sputtered

Table 2. Passivation parameters for a $\mathrm{Si} / \mathrm{SiO}_{2} / \mathrm{ITO}$ contact on an $\mathrm{n}$ - surface.

\begin{tabular}{llll}
\hline Process & $\mathrm{SiO}_{2}$ thickness $(\AA)$ & $\begin{array}{l}J_{\text {o, contact }} \text {-one side } \\
\left(\mathrm{fA} / \mathrm{cm}^{2}\right)\end{array}$ & $i \mathrm{~V}_{o c}(\mathrm{mV})$ \\
\hline 1- As-grown & 900 & 2.2 & 691 \\
2- HF Etch 1 & 194 & 8.6 & 676 \\
3- HF Etch 2 & 45.2 & 8.2 & 650 \\
4- HF Etch 3 & 43.6 & 10.75 & 625 \\
5- ITO as-grown & 43.6 & 1865 & 504 \\
6- FGA \#1 & 43.6 & 55.5 & 633 \\
7- FGA \#2 & 43.6 & 92.5 & 635 \\
\hline
\end{tabular}


deposited onto both sides of the wafer following the same deposition parameters described above. The passivation quality was severely decreased (Table 2 , line 5 ) presumably for the same reasons as with the $\mathrm{n}+$ surface. The passivation was improved by annealing the sample in forming gas for 45 mins at $450{ }^{\circ} \mathrm{C}$ (Table 2, line 6). Another forming gas anneal had little effect on the passivation quality (Table 2, line 7 ). The final passivation quality was characterized by a $J_{0, \text { contact }}$ of $92.5 \mathrm{fA} / \mathrm{cm}^{2}$ with an $i V_{o c}$ of $635 \mathrm{mV}$. For the $\mathrm{n}$ - surface the passivation quality $\left(J_{0, \text { contact }}\right)$ was not fully restored after the ITO layer was deposited in contrast to the $\mathrm{n}+$ surface. Next, a metal $(\mathrm{Ti} / \mathrm{Pd} / \mathrm{Ag} / \mathrm{Pd})$ patterned TLM contact was e-beamed deposited onto the polished-side ITO layer. The ITO was then etched away between the contacts down to the $\mathrm{SiO}_{2}$ layer to provide electrical isolation between the contacts. The contact was found to be ohmic with a contact resistivity of $11.5 \mathrm{mOhms}-\mathrm{cm}^{2}$. Overall, the $\mathrm{ITO} / \mathrm{SiO}_{2}$ contact to low doped $\mathrm{n}^{-}$c-Si surfaces showed excellent contact resistivity, but was about 10-20x higher in $J_{0, \text { contact }}$ compared with a$\mathrm{Si} / \mathrm{Si}$ or $\mathrm{pc}-\mathrm{Si} / \mathrm{SiO}_{2}$ passivated contacts, but over an order of magnitude better than a metal/Si contact.[9]

\section{Optimized contact area for passivated contacts.}

As mentioned above, contacts can be characterized by their ability to passivate $\left(J_{0, \text { contact }}\right)$ and conduct $\left(\rho_{\text {contact }}\right)$. This pair of contact parameters greatly influence high efficiency devices and set an optimum contact area fraction coverage. For solar cells, $J_{0_{-} \text {total }}$ and $r_{\text {series_total, }}$, along with an assumed $J_{s c}$, fully describe the cell output characteristics (ignoring $\mathrm{R}_{\text {shunt }}$ ). The efficiency is given by

$$
\eta=F F * J_{s c} * V_{o c}=F F\left(r_{s}, J_{s c}, J_{o}\right) * J_{s c} * k T * \operatorname{Ln}\left(\frac{J_{s c}}{J_{o}}\right)
$$

where the fill factor, FF, is a function of $r_{s_{-} \text {total }}, J_{0 \_ \text {total }}$ and $J_{s c}$ through the Lambert $W$-Function.[10] Fig. 3 describes the many regions of a solar cell that individually contribute to $J_{0_{-} \text {total }}$ and $r_{s_{-} \text {total }}$. We define $J_{0_{-} \text {total }}$ by

$$
J_{o_{-} \text {total }}=J_{o_{-} \text {back_contact }} * A f_{\text {back_contact }}+J_{o_{-} \text {back_surface }}\left(1-A f_{\text {back_contact }}\right)+J_{o_{-} \text {everything_else }}
$$

where $J_{0 \_ \text {everything_else }}$ includes contributions from the emitter, front contacts and the bulk and $A_{f}$ is the contact area fraction. In a similar fashion $r_{s_{-} \text {total }}$ is defined by

$$
r_{s_{-} \text {total }}=\frac{\rho_{\text {back_contact }}}{A f_{\text {back_contact }}}+r_{s_{-} \text {everything_else }}
$$

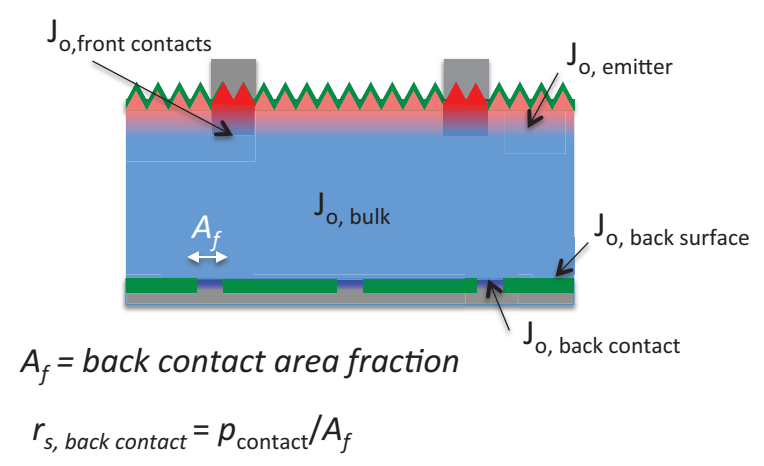

Fig. 3. Cell diagram showing regions of recombination. 
Substituting equations (2) and (3) into equation (1), the efficiency can be optimized as a function of $J_{0 \_ \text {back_contact }}$ and $\rho_{\text {_back_contact }}$ with respect to the back contact area fraction. Figures 4 and 5 show iso-efficiency contours and optimum contact area contours as functions of $J_{0 \_ \text {back }}$ contact and $\rho_{-}$back_contact. $J_{0 \_ \text {back_surface }}=1 \mathrm{fA} / \mathrm{cm}^{2}$ which is a reasonably low value attainable by thermal $\mathrm{SiO}_{2}$ passivation. For Fig. 4 the $J_{s c}, J_{0 \_ \text {everything_else }}$ and $r_{\text {everything_else }}$ were taken from the record HIT cell developed by Panasonic.[1] The Figures easily identify the necessary passivation and contact resistivity needed for a given efficiency along with an optimized contact area. Note that there is an upper limit to the contact resistivity that will give high efficiency devices $\left(\sim 0.6 \mathrm{ohm}-\mathrm{cm}^{2}\right)$. The blue diamond placed on Fig. 4 shows the $J_{0 \_ \text {back_contact }}$ and the $\rho_{\text {back_contact }}$ values of the $\mathrm{Si} / \mathrm{a}-\mathrm{Si}$ passivated contact for the

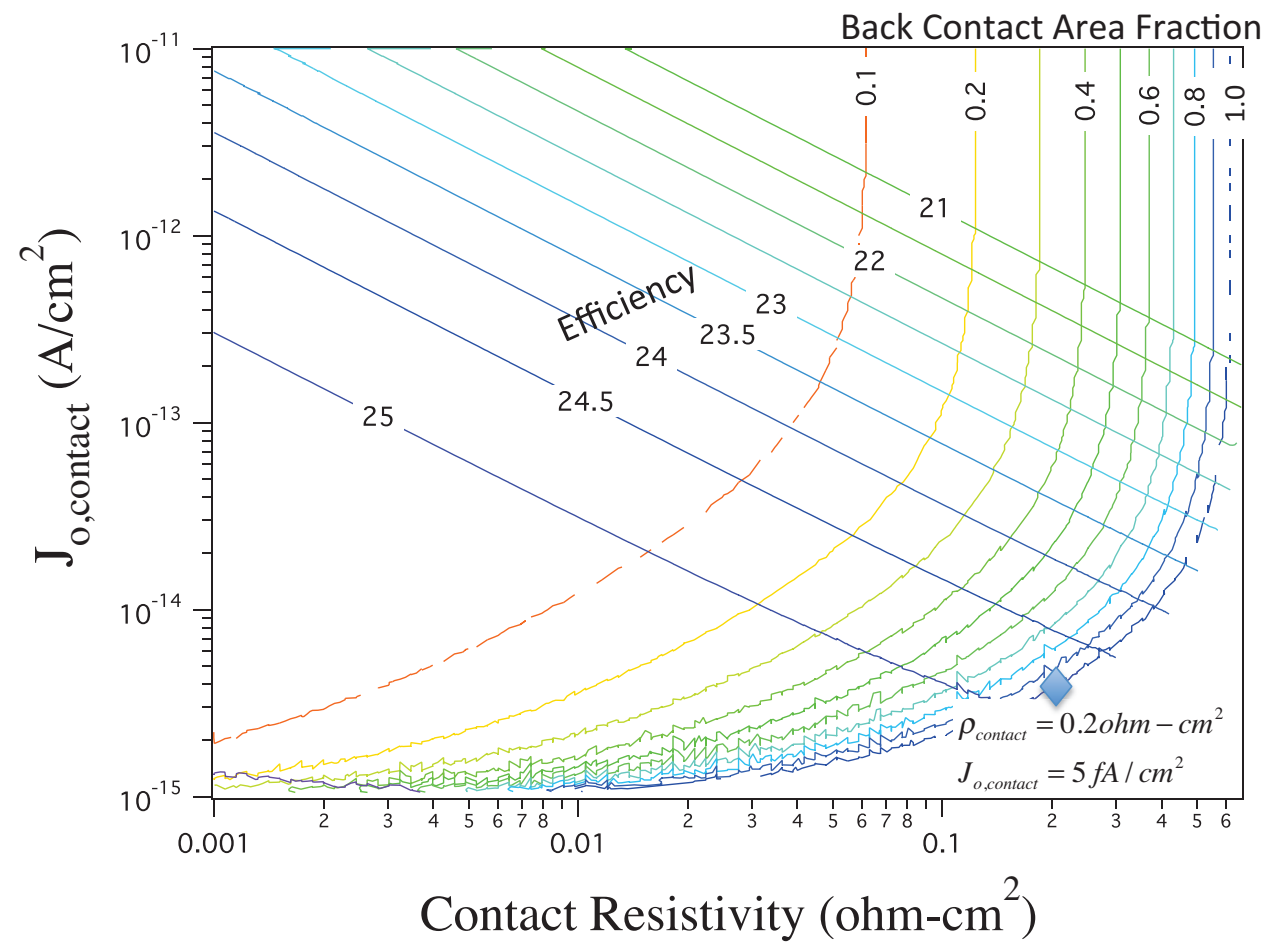

Fig. 4. Iso-efficiency and back contact area fractions as a function of $\mathrm{J}_{0, \text { contact }}$ and back contact resistivity for a device similar to the Panasonic HIT device.

HIT cell. Note that the diagram correctly predicts the efficiency of the $24.7 \%$ device and the necessity of the full area contact due to the relatively high contact resistivity. The $\rho_{-}$back_contact of $0.2 \mathrm{ohm}-\mathrm{cm}^{2}$ would limit the use of this contact in a very efficient interdigitated back contact configuration due to a high series resistance for a contact area fraction less than one. Fig. 5 shows a similar diagram as Fig. 4 but calculated using the values of a recently published cell with a full area $\mathrm{Si} / \mathrm{SiO}_{2} /$ pc-Si passivated contact.[4] The open red square in this diagram 


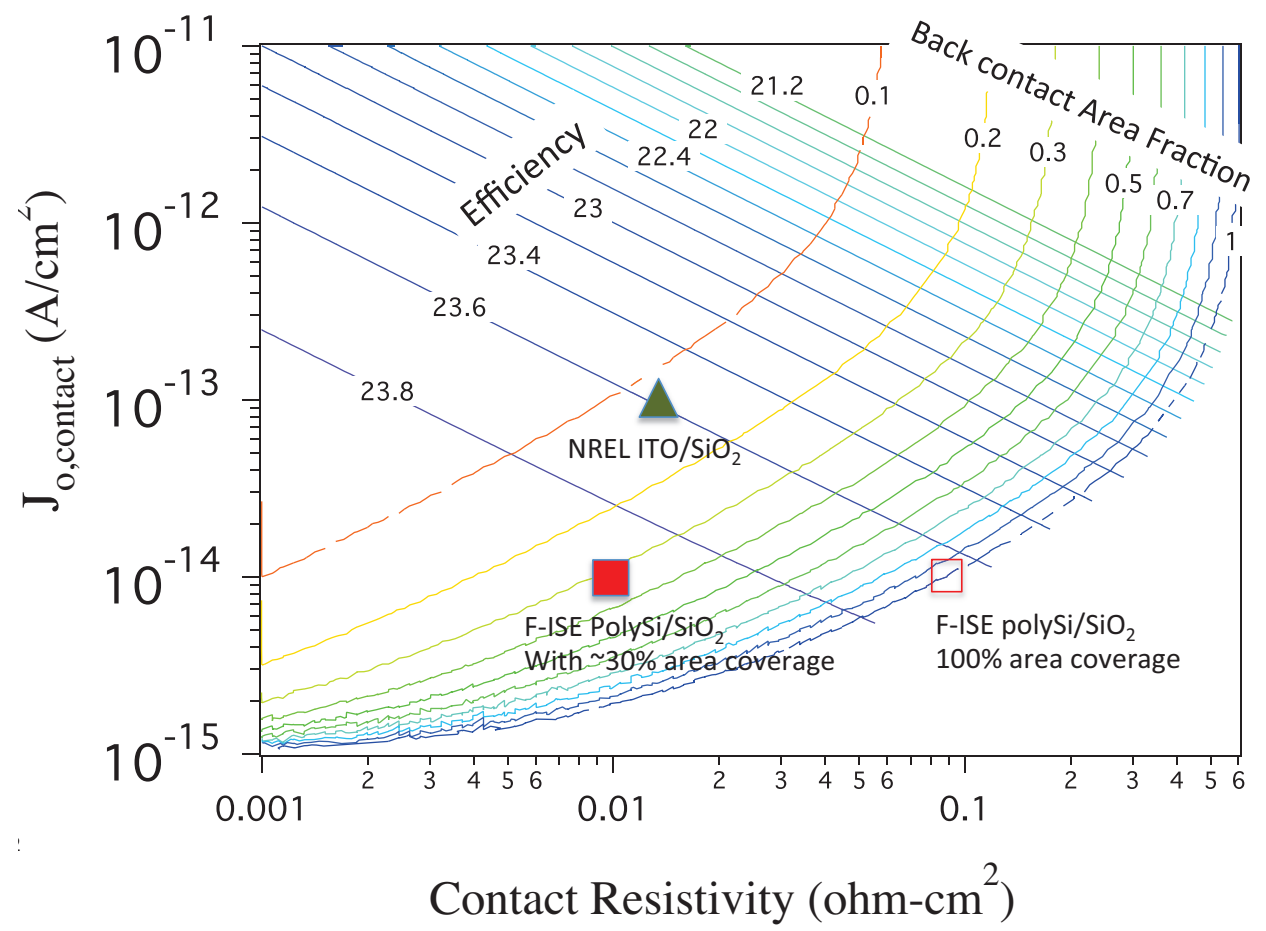

Fig. 5. Iso-efficiency and back contact area fraction contours as a function of $\mathrm{J}_{0 \text {,contact }}$ and back contact resistivity. The input parameters are similar to the device by Feldmann et al. The symbols are described in the text.

shows the placement of their full area contact on the diagram and correctly gives their excellent efficiency of 23.7\%. Careful observation shows that this device could actually increase in efficiency by decreasing the back contact area coverage to about $30 \%$ (solid red square) and instead passivate the uncontacted back surface with a thick, high temperature oxide (assumed to give a $J_{0}=1 \mathrm{fA} / \mathrm{cm}^{2}$ ). This highlights one of the utilities of this diagram.

We can use Fig. 5 to compare our $\mathrm{Si} / \mathrm{SiO}_{2} / \mathrm{ITO}$ contacts with the $\mathrm{Si} / \mathrm{SiO}_{2} / \mathrm{pc}$-Si contacts if processed on a similar device. The green triangle on Fig. 5 indicates our best $\mathrm{Si}_{\mathrm{SiO}} / \mathrm{ITO}$ contact and predicts an efficiency of $23.6 \%$. Because the contact resistivity of the $\mathrm{Si} / \mathrm{SiO}_{2} / \mathrm{ITO}$ contact resistivity is about the same as the $\mathrm{pc}-\mathrm{Si} / \mathrm{SiO}_{2}$ contact, but has a higher $J_{0, \text { contact }}$ value, the optimum contact area fraction coverage is about $10-15 \%$. Practically speaking an optimized full area contact would likely be the simplest and most cost effective back contact for mass production.

\section{Discussion}

We developed a passivated contact to $n$-type silicon using a layer stack of $\mathrm{Si} / \mathrm{SiO}_{2} / \mathrm{ITO} /$ metal. The contact is an improvement over metal/Si contacts in terms of passivation, but lacks the single-digit $\mathrm{fA} / \mathrm{cm}^{2}$ quality of other passivated contacts to date. Though the contact parameters are not as good as the $\mathrm{Si} / \mathrm{SiO}_{2} / \mathrm{pc}-\mathrm{Si}$ contacts, the $\mathrm{Si} / \mathrm{SiO}_{2} / \mathrm{ITO}$ contacts are still quite respectable, are better than metal/Si contacts and may be of benefit to some lowtemperature device designs. Optically, there may be advantages to having a contacting layer with an index of refraction of about $\mathrm{n} \sim 2$ (ITO) compared with $\mathrm{n} \sim 4$ (pc-Si). However, if the contacts are in the back of the device, and the contacting layers are about $30 \mathrm{~nm}$ thick, there is little advantage to having ITO replace pc-Si due to the low absorption coefficient beyond $1000 \mathrm{~nm}$ in pc-Si. Optical models for the $\mathrm{Si} / \mathrm{SiO}_{2} / \mathrm{ITO}$ and $\mathrm{Si} / \mathrm{SiO}_{2} / \mathrm{pc}-\mathrm{Si}$ contacts using Wafer Optics Calculator (PVlighthouse.com) reveal similar parasitic absorption for both contacts amounting to less than $0.1 \mathrm{~mA} / \mathrm{cm}^{2}$ in the rear contacting films. However, the high bandgap and higher transparency of ITO 
make it a much better choice for a front contact where the $\mathrm{n} \sim 2$ also allows it to be an effective anti-reflective coating.

Much more experimentation is needed on the $\mathrm{Si} / \mathrm{SiO}_{2} / \mathrm{ITO}$ contacts to better understand the nature of the passivation and the transport of carriers between the $\mathrm{Si}$ and ITO through the $\mathrm{SiO}_{2}$ layer. Other TCOs like SnO:F or $\mathrm{ZnO}$ may offer benefits not afforded by ITO including more favorable band alignments and work functions, higher temperature processing, lower cost and gentler deposition techniques.

Finally, it is still an open question as to why the passivation quality decreases for $\mathrm{SiO}_{2}$ layers less than $30 \AA$ on a $\mathrm{Si}$ surface (Fig. 2). One reason may be that defect levels at the $\mathrm{SiO}_{2} /$ air interface begin to influence the recombination rate by allowing wavefunction overlap between states in the $\mathrm{Si}$ and defective $\mathrm{states}$ at the $\mathrm{SiO} /$ air interface. $\mathrm{SiO}_{2}$ mainly provides chemical passivation to a $\mathrm{Si}$ surface, as opposed to field passivation via fixed charge. If thinning of the $\mathrm{SiO}_{2}$ layer removes the fixed charge, there should still be decent chemical passivation to the $\mathrm{Si} / \mathrm{SiO}_{2}$ interface. The chemical passivation of the $\mathrm{Si} / \mathrm{SiO}_{2}$ interface should not be disturbed due to the thinning of the $\mathrm{SiO}_{2}$. A complete understanding of the data in Fig. 3 must account for the fact that the surface passivation of thin $\mathrm{SiO}_{2}$ can be nearly fully restored (to that of thick $\mathrm{SiO}_{2}$ ) by placing a doped pc-Si (or a-Si) layer on top of the $\mathrm{SiO}_{2}$ layer. This layer certainly provides some field passivation, but may also tie up dangling bonds at the $\mathrm{SiO} / \mathrm{pc}_{2}$ $\mathrm{Si}$ interface. Further study of this interface and the $\mathrm{SiO}_{2} / \mathrm{ITO}$ interface is needed to guide further passivated contact developments.

\section{Acknowledgements}

The authors would like to thank Anna Duda for depositing the e-beam metal contacts for this work. This work was supported by the U.S. Department of Energy under Contract No. DE-AC36-08-GO28308 with the National Renewable Energy Laboratory.

\section{References}

[1] Panasonic Panasonic HIT solar cell achieves World's highest conversion efficiency of 24.7\% at Research Level. 2013.

[2] Garcia-Alonso D, Smit S, Bordihn S, and Kessels W, Silicon passivation and tunneling contact formation by atomic layer deposited Al2O3/ZnO stacks. Semiconductor Science and Technology, 2013. 28.

[3] Bullock J and Cuevas A, Passivation of aluminium-n+ silicon contacts for solar cells by ultrathin Al2O3 and SiO2 dielectric layers. Phys. Status Solidi RRL, 2013. 1-4.

[4] Feldmann F, Bivour M, Reichel C, Hermle M, and Glunz SW, A passivated rear contact for high-efficiency n-type silicon solar cells enabling high Vocs and FF>82\%. in 28th European PV solar energy conference and exhibition 2013. Paris, France.

[5] Coutts TJ, Young DL, and Gessert TA, Modeling, Characterization, and Properties of Transparent conducting oxides. Handbook of Transparent Conductors, ed. D.S. Ginley, H. Hosono, and D.C. Paine, New York: Springer 2010.

[6] Young DL, Branz HM, Liu F, Reedy R, To B, and Wang Q, Electron Transport and band structure in phosporus-doped polycrystalline silicon films. Journal of Applied Physics, 2009. 105(3): p. 033715.

[7] Klein A, Körber C, Wachau A, Säuberlich F, Gassenbauer Y, Harvey SP, Proffit DE, and Mason TO, Transparent Conducting Oxides for Photovoltaics: Manipulation of Fermi Level, Work Function and Energy Band Alignment. Materials, 2010. 3(11): p. $4892-4914$.

[8] Ng KK and Card HC, Asymmetry in the SiO 2 tunneling barriers to electrons and holes. Journal of Applied Physics, 1980. 51.

[9] Kerr MJ, Schmidt J, Cuevas A, and Bultman JH, Surface recombination velocity of phosphorus-diffused silicon solar cell emitters passivated with plasma enhanced chemical vapor deposited silicon nitride and thermal silicon oxide. Journal of Applied Physics, 2001.89.

[10] Khanna A, Mueller T, Stangl RA, Hoex B, Basu PK, and Aberle AG, A fill factor loss analysis method for silicon wafer solar cells. IEEE Journal of Photovoltaics, 2013. 3(4). 